\title{
Mark Twain, la argumentación y la persuasión: reseña del capítulo "From Conceptual Meaning to Intentional Meaning in Argumentative Persuasion: A Literary Case"
}

Luis Luques-Álvarez *

Magíster en Lengua Española, Facultad de Filosofía y Letras, Universidad Autónoma de Madrid (UAM), Madrid, España. Periodista de la Agencia Aceprensa. Correo electrónico:

luisluque24@yahoo.com

Cómo citar este artículo: Luques-Álvarez, Luis. "Mark Twain, la argumentación y la persuasión: reseña del capítulo 'From Conceptual Meaning to Intentional Meaning in Argumentative Persuasion: A Literary Case'”. Rastros Rostros 18.32 (2016): 87-89. Impreso. doi: http://dx.doi.org/10.16925/ ra.v18i32.1320.
Aquel sábado prometía para Tom Sawyer ser un día verdaderamente desdichado. Como única "distracción", la tía Polly le había entregado una brocha y un bote de pintura, y le había ordenado pintar una cerca de madera. Pero el buen uso de las técnicas comunicativas le ayudó a terminar la jornada más descansado de lo que hubiera podido imaginar y con recompensa añadida.

En el capítulo "From Conceptual Meaning to Intentional Meaning in Argumentative Persuasion: A Literary Case", incluido en Con/Texts of Persuasion, la doctora María Azucena Penas-Ibáñez, de la Universidad Autónoma de Madrid, extrae un fragmento de la conocida obra de Mark Twain y disecciona la estrategia lingüística verbal y extraverbal adoptada por el chicuelo para librarse de pintar: un amigo de Tom, Ben Rogers, es el interlocutor que aparece en el momento preciso, como Hércules a los ojos de Atlas, para quitarle de encima el peso de tan ímproba tarea.

El plan tiene etapas y necesita de cierta dosis de paciencia. Al inicial saludo burlesco de Ben, quien además se presenta comiendo una apetecible manzana, Tom no reacciona. Está en apariencia tan "abstraído" por sus deberes, pone tanto "empeño" en estos, que todo lo demás le parece superfluo. Su propósito es claro: hacerle apetecible a Ben el acto de sustituirlo en la faena, aunque el chico no se hubiera levantado esa mañana con la idea de pegar palo al agua. Tom quiere aún más: desea hacerse con la fruta.

Como, en primera instancia, el trabajo no es una actividad que desate el apetito humano, Tom debe manipular la realidad y convencer a su interlocutor de que este es lo más gratificante que puede haber en una especie de corrupción de los argumentos. Tendrá los medios para esto. Según recuerda Penas-Ibáñez, la comunicación persuasiva se apoya en la creatividad esencialmente: 
[...] mediante el empleo de argumentos sociales y universales incontestables, y mediante el manejo de todos los signos comunicativos posibles, lenguajes verbales y no verbales, eligiendo la expresión y el orden en que deben emplearse, porque se conoce la respuesta emocional a la que conducen. (116)

No vale aquí la alusión directa, sino otra estrategia: la inferencia. El "interés" de Tom, su vista fija en la verja de madera tras cada uno de sus "magistrales" brochazos, dice mucho más que una forzada expresión dirigida a convencer de que pintar cercas un sábado es la mejor tarea del mundo. Penas-Ibáñez anota la habilidad de sugerir de Tom, toda vez que una afirmación explícita haría más fácil la contraargumentación, y es esa aparente y silenciosa absorción lo que motiva la curiosidad de Ben, que cambia su objeto de entretenimiento, sin percatarse de que ha sido su interlocutor quien lo ha reconducido a un nuevo propósito: si Tom halla en la pintura una causa de alegría, aún más convincente que ir a darse un chapuzón al Missisipi, se infiere que es una cosa positiva. El sobrino de Polly ha sabido redirigir la situación comunicativa, y su amigo ha comenzado a entrar muy gustosamente en la trampa.

La estrategia argumentativa de Tom a lo largo del proceso es - sin entrar en engorrosas consideraciones éticas que no vienen al caso- ejemplar: de hacerse el desentendido ante una primera provocación de Ben - “iji, ji! Te han hecho polvo, ¿eh?”- y mantenerse "ensimismado" en la faena, pasa a mostrarse ambiguo ante el interrogante de si considera la pintura un trabajo, ergo, un insufrible fastidio en sábado, a lo que responde "tal vez sí, tal vez no", y así hasta que, en el intercambio, le confiesa al de la manzana que no siempre un muchacho tiene la "oportunidad" de pintar una valla de ese tipo. De fastidio, la pintura ha pasado a ser honor inmerecido. ¿Es de extrañarse que Ben, tras intentar primeramente hincar diente en el orgullo de Tom, haya pasado a querer emularlo, rogándole que le permita empuñar la brocha?

El protagonista, sin embargo, sabedor de donde ha llegado y consciente de que un segundo objetivo, la manzana, todavía está fuera de su alcance, busca reforzar su estado, y lo hace aludiendo a una autoridad superior: la tía Polly, que le ha encomendado a él y solo a él la tarea. Penas-Ibáñez describe el ocurrente recurso del chico: “[...] si quieres conducir [...] la escalada progresiva del plan hacia un pacto ventajoso para ti, debes informar o recordar puntos de vista sostenidos por personas con una opinión autorizada, pero que estén ausentes y no puedan contradecirte, por lo que no parecerás irrazonable" (127). De tal modo, y como el orden universal se trastocaría si Tom accediera a delegar su responsabilidad en otro, el "sacrificio" demanda un gesto de Ben. La manzana es la moneda de cambio.

Es así como el pequeño héroe de Mark Twain termina la jornada sentado, viendo desfilar a una cohorte de chicuelos que, por el "honor" de pintar un rato, le van entregando "joyas" varias: desde un fragmento de botella azul hasta un pequeño gato tuerto y una llave que no abría ninguna puerta.

Todo ello ha sido posible, curiosamente, no por el valor intrínseco de una actividad tan meritoria pero agotadora como el trabajo físico, sino por la intención de trastocar la percepción acerca de este de los que interactúan con Tom, un proceso en que el hablante reconduce el sentido del diálogo y confiere a la realidad un valor que depende únicamente de sus intereses. Según Penas-Ibáñez, es “[...] de la credibilidad y de la relevancia del punto de vista adoptado por los participantes en la interacción comunicativa[...]" que depende que un mensaje sea aceptado.

De lo que sí no cabe duda es de que el bueno de Tom, sin tener conciencia de los mecanismos conceptuales de su acción, de los que ha hecho un análisis pormenorizado y riguroso Penas-Ibáñez en el capítulo que ahora reseño, se las ha ingeniado para ser tremendamente persuasivo y arrastrar al trabajo, con su divertido embuste, a su ingenua tropa de amigos.

El análisis llevado a cabo en este capítulo es muy exhaustivo en cuanto a estrategias comunicativas de dirección y manipulación de hipótesis en los mensajes. Siguiendo la teoría de la argumentación se construye una serie de mapas o redes conceptuales con vistas a reconstruir cómo un estado de proposiciones condiciona la aparición de los siguientes estados proposicionales. El estudio se basa en el método ostensivo-inferencial, así como en los principios de cooperación y relevancia aplicados a los actos de habla ilocutivos y perlocutivos. A través de la selección de un pasaje muy divertido de la famosa novela de Mark Twain, se describe el modo en que sucesos comunicativos son manejados de forma usual en términos de secuencias de negociación gradual.

El estudio llevado a cabo, además de su calidad y rigor, resulta muy ameno y accesible a los lectores, sean estos expertos en la materia o estudiantes interesados en la comunicación, la argumentación y la semántica textual. Se hace un retrato certero de las 
relaciones conversacionales, los fines y metas que se persiguen en ellas, así como las conductas legítimas y no tan legítimas que en ocasiones se tienen.

El capítulo de la doctora María Azucena PenasIbáñez se inscribe dentro de una obra colectiva editada por Beatriz Penas, Micaela Muñoz y María Conejero, y publicada por la prestigiosa Edition Reichenberger en su extensa y acreditada colección Problemata Literaria.

\section{Referencias}

Penas-Ibáñez, María Azucena. "From conceptual meaning to intentional meaning in argumentative persuasion. A literary case". Con/Texts of Persuasion. Ed. Beatriz Penas, Micaela Muñoz y María Conejero. Kassel: Edition Reichenberger, 2011. 113-134. Impreso. 